Paideusis

\title{
Higher Education, Globalization and the Critical Emergence of Diversity
}

\section{Peter D. Hershock}

Volume 19, Number 1, 2010

URI: https://id.erudit.org/iderudit/1072321ar

DOI: https://doi.org/10.7202/1072321ar

See table of contents

Publisher(s)

Canadian Philosophy of Education Society

ISSN

0838-4517 (print)

1916-0348 (digital)

Explore this journal

Cite this article

Hershock, P. (2010). Higher Education, Globalization and the Critical Emergence of Diversity. Paideusis, 19(1), 29-42.

https://doi.org/10.7202/1072321ar
Article abstract

Complex, risk-generating and predicament-laden patterns of global interdependence pose significant imperatives for radically reframing the purposes and provision of higher education. Changes already ongoing in higher education reflect and respond to global dynamics that are intensifying interdependence and, at the same time, deepening inequalities both within and among societies. Recognizing this is to recognize the need to question whether the arcs of change in higher education should remain passively entrained with globalization-driven magnifications and multiplications of difference, or whether higher education can and should play a unique and critical role in reorienting the dynamics of global interdependence. This paper argues that if current trends toward both institutional and epistemic differentiation can be inflected toward enhancing diversification-rather than mere variation-21st-century higher education can come to serve as a global relational commons crucial to realizing ever more deeply shared and equitable expressions of global flourishing and public good. (c) Peter D. Hershock, 2010

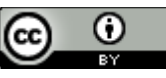

This document is protected by copyright law. Use of the services of Érudit (including reproduction) is subject to its terms and conditions, which can be viewed online.

https://apropos.erudit.org/en/users/policy-on-use/ 


\title{
Higher Education, Globalization and the Critical Emergence of Diversity
}

\author{
PETER D. HERSHOCK \\ East-West Center, Honolulu, Hawai'i, USA
}

\begin{abstract}
Complex, risk-generating and predicament-laden patterns of global interdependence pose significant imperatives for radically reframing the purposes and provision of higher education. Changes already ongoing in higher education reflect and respond to global dynamics that are intensiffing interdependence and, at the same time, deepening inequalities both within and among societies. Recognizing this is to recognize the need to question whether the arcs of change in higher education should remain passively entrained with globalization-driven magnifications and multiplications of difference, or whether bigher education can and should play a unique and critical role in reorienting the dynamics of global interdependence. This paper argues that if current trends toward both institutional and epistemic differentiation can be inflected toward enbancing diversification — rather than mere variation-21st-century higher education can come to serve as a global relational commons crucial to realizing ever more deeply shared and equitable expressions of global flourishing and public good.
\end{abstract}

Contrary to the hopes of some and the fears of others, highly intensified globalization processes have not generally brought about widening and deepening global consensus (Appudarai, 1996). For evidence, one need look no further than the disjointed and diffuse response to the ever more distressing realities of accelerating climate change, the persistence of global hunger, or the tragic elusiveness of educationfor-all. The communications revolution of the last half century notwithstanding, the world remains significantly (and not only incidentally) divided. It would seem that if we now live in a so-called global village, it is a village without a commons.

It is thus quite remarkable that-as is readily demonstrated by conducting an Internet search pairing "education" with such keywords as "crisis" and "reform"- - one of the few areas of passionate global consensus centers on perceptions that our formal education systems are falling short of meeting educational needs and desires. Apparently complex in origin, these perceptions are expressed in terms that resonate variously with critical discourses on educational standards, quality and market alignment, with concerns about citizenship and values, and with growing public/private tensions among the purposes, provision and funding of education.

In what follows, I want to present a set of conceptual lenses that help bring into focus how currently widespread perceptions of educational crisis are not best seen primarily as evidence of the failures of specific schools, curricula, teachers or students, but rather as evidence of the implosion of what Tyack and Cuban (1995) have referred to as a prevailing educational "grammar," or what John Hawkins (2007) has more recently and productively referred to as the "globally dominant educational paradigm." As detailed by Kuhn (1996), the imminent failure of a scientific paradigm is signaled by mounting difficulties in reconciling the empirical results of scientific activity with an existing spectrum

(C) Copyright 2010. The author, Peter Hershock, assigns to Paideusis the right of first publication and educational and non-profit institutions a non-exclusive license to use this document for personal use and in courses of instruction provided that the article is used in full and this copyright statement is reproduced. Any other usage is probibited without the express permission of the author. 
of theoretical orientations, and paradigm change is not primarily an effect of investing greater resources in existing research agendas, but rather a function of challenging basic presuppositions in such a way as to realize a new and conflict-resolving complexion of the syntactic and semantic dimensions of science. Likewise, seeing contemporary educational crises as evidence of paradigm failure directs attention to the need for a fundamental and emergent reorganization of the means-to and meaning-of education.

More specifically, I want to use these conceptual lenses to explore possibilities for challenging the modern, universalist presuppositions built into the dominant educational paradigm, and for contributing to the emergence of apt alternatives to it by rethinking the meaning of differenceenvisioning arcs of change suited to more effectively aligning the provision and purposes of higher education with the aim of more equitably orienting the dynamics of global interdependence.

\section{Four Educationally Significant Arcs of Change}

Among the arcs of change evident in contemporary globalization processes, four seem to me to be particularly relevant for understanding the conditions leading to broad and deepening consensus regarding the shortfalls of education worldwide.

First, while contemporary globalization processes have clearly led to homogenizing or integrative linkages among local, national, regional and global "flows" of goods, services, people, ideas and ideals, they have also led to fragmenting effects (Stiglitz, 2003; Rosenau, 2003). Thus, alongside the kinds of institutional convergence that enable the use of credit cards and cell-phones around the world and the rise of global popular cultures, contemporary globalization processes have also proven conducive to the rise of separatist political movements, the resurgence of traditional religious identities, the exacerbation of class structures, and the proliferation of both niche markets and lifestyles (Appadurai, 1996; Robinson, 2004). At contemporary scales and scopes, globalization is not only an intensifier of interdependence, it is a multiplier and magnifier of differences.

Second, the free-market logic of sustaining economic growth by both expanding market reach and intensifying market density has not only proven highly conducive to the proliferation of niche markets, but also to a radical compression of the consumption-to-waste cycle and a corresponding intensification of the key market values of competition, convenience, control and choice (Harvey, 2006). In tandem, marketization and modernization have brought about a remarkable global intensification of individuation processes, but also a growing tendency to subordinate commitment to choice and to understand community as elective (de Zengotita, 2005). The fluidity and ubiquity of communicative and associational possibilities afforded by the advent of the network society has had the ironic effect of fostering deepening identification of the optimal with the optional.

Third, while considerations of the impacts of globalization have tended to focus somewhat immediately on the dawn of the "information age" and "network society" (Castells, 1996, 1997, 1998), from a more synoptic historical perspective these impacts can usefully be seen as part of a broader shift away from industrial to mental capitalism and from a material to an attention economy. ${ }^{1}$ Mass media and entertainment revenues worldwide are now on par with those of the oil industry, and as demonstrated by both the "Asian" financial crisis of 1997 and the more recent collapse of world stock markets in the fall of 2008, the vitality of the global economy is intimately tied to complex and thus prediction-resistant information and attention flows. Importantly, however, the consumption-to-waste cycle in an information and attention driven economy is very nearly perfect. The half-life of information on the floor of an international stock exchange is just under 10 seconds, and the half-life of scientific and technical knowledge is now estimated at 18 months. Under complex globalization, the

\footnotetext{
${ }^{1}$ On the notion of the attention economy in relation to globalization dynamics, see: Hershock (1999), Lanham (2006) and Franck (1998).
} 
most basic communicative medium is the message — a datum compelling immediate assessment and response-and the information age is thus an age of increasingly rapid or unreflective decision making. ${ }^{2}$

Finally, it has become evident over especially the past four decades that industrial modernization has crossed a critical scale threshold, taking a "reflexive" turn beyond which its further successes and growth depend on the ironic production of expanded threats and heightened risks in the face of which responsible decisions must nevertheless be made (Beck, Giddens and Lash, 1994). In Ulrich Beck's (1999) terms, having crossed this threshold, the continued "successes" of industrial modernization generate conditions suited to the advent of a "world risk society" in which decision-making percolates into all aspects of life, from the personal to the global, and in which the scope of both individual and collective responsibility is continuously expanded. The advent of world risk society is the experience of confrontation with ongoing and indeed intensifying conflicts among our own values and interests.

\section{From Problems to Predicaments: A Change of Eras}

Taken together, these arcs of change compel recognition that we are not only in the midst of an era of unprecedentedly rapid and deep change, but also a change of eras. I would describe this as a shift from a global era of problem-solution to one of predicament-resolution. Problems arise when changing circumstances make evident the failure of existing practices to meet abiding needs and interests. Problems are solved by developing new or improved means for arriving at ends we fully intend to continue pursuing. Thus, gas-electric hybrid motor technology offers a solution to the problem of high fuel costs, enabling us to reduce transportation costs without significantly altering our transportation practices, leaving our "automobile culture" intact. Predicaments occur when changing circumstances lead to the incidence and/or awareness of conflicts among our own values, interests, and patterns of development. Unlike problems, predicaments cannot be solved. Predicaments do not primarily draw into question the means of satisfying our needs and furthering our interests, but rather their meaning. Predicaments can only be resolved, where resolution connotes both highly detailed clarity regarding factual dynamics and clear-and clearly shared_commitments. ${ }^{3}$

The fact that nearly one billion people continue to go hungry in a world of food excesses is not a problem, it is a predicament. This is not to dismiss the tragic and indeed horrific consequences of chronic hunger suffered by nearly one out of every seven people on the planet. Rather, recognizing that global hunger is a predicament is to necessitate coming to grips with the fact that the world's hungry remain so, not because of any overall food shortages, but because of persistently entrenched conflicts among our economic, political, and cultural values. World hunger does not persist because we lack the technical means for the basic food needs of all to be sustainably addressed. It persists because globally we have not deemed it worth making the changes needed - a failure that is ethical rather than technical, and one for which responsibility cannot ultimately be sidestepped or outsourced. Human-induced climate variability and volatility likewise force confrontation with conflicts among our own values regarding the meanings of "a good life," "progress," and a "good, clean environment."

Seen in the context of globalization processes that, in addition to their integrative dynamics, are serving as multipliers and magnifiers of differences, the shift from a world of problems to a world of predicaments forces confrontation with a deepening aporia - an impasse or paradox centered on the means-to and meaning-of difference, and one felt with particular intensity in higher education. On one hand, we find ourselves faced with needs to recognize and respect difference to historically unprecedented degrees, going beyond simply tolerating differences from and among others to enabling

\footnotetext{
${ }^{2}$ For an insightful consideration of information in the context of mass media and communications technology, see Luhmann (2000); for a critical treatment of information in political context, see Lash (2002).

${ }^{3}$ Expanded discussions of the distinction between problems and predicaments can be found in Hershock (2006), especially Chapter 8, "Educating for Virtuosity", and in Hershock (2007a and 2007b).
} 
differences to matter more, not less than they ever have. On the other hand, we also find ourselves faced with glaring needs to engage in ever more robust and encompassing pursuits of global common cause, subsuming differences within shared and deepening commitments.

This aporia can be seen on one hand as expressing a particular legacy of modern struggles to reconcile the contrary values of universalism and individualism - a struggle that Mark Taylor (1987) has traced at a conceptual level in the philosophical transit from $19^{\text {th }}$-century Hegelian system building to the late $20^{\text {th }}$-century postmodernism of Levinas, Derrida and Deleuze. On the other hand, as David Harvey (1996) has masterfully demonstrated, it can also be seen as the culmination of an interweaving of concerns about justice and difference that can be traced economically from $19^{\text {th }}$-century critiques of global capital through the "alternatives to globalization" movements of the last quarter of the $20^{\text {th }}$ century. At least over the last two centuries, in its religious, philosophical, social, political, economic, and cultural dimensions, global history has increasingly been "a history of the struggle with the endlessly complex problems of difference and otherness" (Taylor, 1987: xxi).

Granted that higher education is functionally entrained with the full spectrum of any society's social, economic, political, technological, and cultural dynamics, and also deeply embedded within complexly shifting patterns of global interdependence that constitute their overarching context, it is hardly surprising that this aporia is experienced with particular force in higher education. And this encourages asking two important sets of questions. First, how does this aporia of difference affect the means-to and meaning-of higher education? Into what kinds of predicaments is higher education being drawn, and how deeply? Secondly, how might higher education contribute to addressing this aporia? Or more specifically, what are the prospects of higher education contributing to more equitably orienting the dynamics of our ever deepening and widening interdependence?

\section{The Globally Dominant Paradigm of Formal Education: A Modern Artifact}

The now globally dominant paradigm of education was born along with modernity and global markets in the context of a convergence-politically, socially, economically, scientifically, culturally, and technologically — on the values of universalism, autonomy, equality, sovereignty, competition, and control, in response to deep and cripplingly violent religious, ethnic, and political differences that raged across Europe in the late $16^{\text {th }}$ and early $17^{\text {th }}$ centuries..$^{4}$

The essence of this educational paradigm is encapsulated in Peter Ramus' use, in 1576, of "curriculum" in an educational context. In sharp contrast with the then prevailing paradigm of studiocentered learning paradigm in which masters of a given knowledge domain offered individually framed and open-ended tutelage to a wide range of student apprentices, Ramus claimed: first, that knowledge is a quantifiable and deliverable good most efficiently and effectively transferred via standard instructional sequences culminating in predetermined ends; and secondly, that learning consists of acquiring specific bodies of knowledge and competence, by methods that at once express and transfer their deep structure. His use of "curriculum" deftly characterizes the key organizing principle of this new educational paradigm: the Latin word, curriculum, refers to a circular course of standard length once used in chariot competitions. As envisioned through modern lenses, education is ideally universalized, standardized, methodized, and terminal.

The modern paradigm of disciplined (and, indeed, highly disciplinary), curriculum-centered education at once expresses and transmits the deep structure of what Stephen Toulmin (1990) has called cosmopolis-a world ordered and unified "from above" in keeping with modern values of universality, autonomy, equality, sovereignty, competition, and control; a world in which differences are construed as dangerous, contingent, and ultimately irrelevant. This educational paradigm proved quite

${ }^{4}$ Useful reflections on the modern origins and postmodern trajectory of education can be found in Doll (1993) and Doll and Gough (2002). 
compatible with the needs of newly emerging polities in intense colonial and market competition. For roughly two centuries, beginning around the middle of the $18^{\text {th }}$ century, the record of publicly delivered curricular education was a stunning one of accelerating economic growth, heightening productivity, raising per capita incomes, rationalizing population growth, and fostering deeply internalized imaginations of national identity.

Like the processes of industrial modernization with which it has been deeply entrained, educational modernization has been hugely successful. This should not be denied. Yet, there is also no denying that today, education has become a significant nexus of risks and deepening crisis. This is especially true for higher education, which has increasingly come to be seen as misaligned with market and social needs and as profoundly troubled by issues of access and equity associated with the emergence of ever more dense politics of recognition and respect, from the local level to the national, regional and global, but the phenomenon is much more widespread.

My own view is that-in a world compelling ever deepening engagements with difference-the globally dominant approaches to education are laboring under modern biases toward a cosmopolitan agenda of universalized instructional goals and content, delivered and met through standardized methods, resulting in controllably produced problem-solving competencies and the disciplining of differences. Efforts to "internationalize" schools and curricula, the explosion of demand-driven educational opportunities, the capitulation to and celebration of the need for "lifelong learning," and the near canonization of "diversity" as a key institutional goal can all be seen as marking recognition that something new is needed. But such efforts, undertaken as amendments to the existing paradigm, are likely to exacerbate rather than alleviate educational shortfalls. Much as the reflexive turn of modernization from roughly the mid-20 $0^{\text {th }}$ century onward has led to a proliferation of threats and risks as ironic consequences of the successes of industrialization and a world saturated with decision-making, educational modernization has crossed a threshold beyond which its further "successes" produce escalating needs for ever more differentiated and individualized education, recursively and ironically contributing to the production of ever more global patterns of educational predicament and risk.

Given the entrainment of higher education with modernization and marketization-especially as evidenced in the four arcs of change discussed earlier — what we would expect is that $21^{\text {st }}$ century global dynamics will drive us ever more forcefully toward difference-sensitive and difference-producing education. This is already evident in the increasing marketization of higher education; growing emphases on flexible specialization, individualized courses, and student-centered instruction; the proliferation of non-degree, post-baccalaureate programs; and diminishing emphases on the public provision and purposes of higher education. But, in keeping with the logic of productive inequality underlying the operation of free markets, educational differentiation is also showing signs of further exacerbating already severely uneven geographies of educational achievement and excellence. If educational differentiation is to be compatible with greater educational equity, we are in need of a new conception of and relationship with difference.

\section{Re-conceiving Difference: Variety and Diversity}

There has always been a tension in the modern construction of difference, a tension that can be traced back to the twin births of European Enlightenment modernity and global markets. In cosmopolis, all citizens are autonomous individuals with equal opportunities to pursue their sovereign interests. In the commercial/industrial circulatory system, through which cosmopolitan ideals are transformed into daily realities, benefits accrue most rapidly when the topographies of advantage and disadvantage are most uneven, with competitive inequalities translating into accelerating flows in one direction rather than others. Under the auspices of the modern, differences are essentially contingent and subordinated to the needs of respecting a universal human nature; under those of the market, differences serve as a 
basic fuel for exchange, valueless in themselves but crucial to sustaining economic growth and linked (especially under free-market capitalism) to both income and opportunity disparities.

This tension was famously central to Marxist and other criticisms of the marriage of modernity and capitalist markets - a marriage that resulted in the division of humanity into classes that mocked the modern idealization of equality, autonomy and universality. Later $20^{\text {th }}$-century movements for workers' rights, women's suffrage, and universal human rights can be seen as originating in refusals to allow real differences and the tensions they evidence to be glossed over with generic ideals, resulting in the emergence of needs to grapple with what John Rawls (1999) referred to as the intrinsic "plurality of modern societies" in the realization of justice, and the burgeoning in the final decade of the $20^{\text {th }}$ century of the politics of recognition and respect and the valorization of multiculturalism. ${ }^{5}$ But it was only in the final third of the century that difference came to be taken seriously, with "postmodern" thinkers like Emmanuel Levinas and Gilles Deleuze insisting that it is not sameness or its valorization as equality that is ethically and ontologically primary, but difference. Since then, issues of difference-especially in terms of gender, race, ethnicity, class and religion, but also learning styles, intelligences, and cultural norms - have come into ever increasing prominence.

But while the necessity of taking differences seriously into account are now quite widely recognized (if not always celebrated), they continue to be seen as evidencing problems to be solved, not through the largely discredited method of assimilation, but rather through just strategies that enable differences to be conserved while insuring that they do not translate into capability- and opportunitycorroding inequalities. That is, the overwhelming tendency is to imagine difference as an external relation and to ground the pursuit of equity in the realization of equalities of opportunity. Here, the U.S. civil rights movement and the more recent global movement to insure universal recognition and respect not only for "first generation" political and civil rights, but also "second generation" social, economic, and cultural rights can be seen as positive outcomes of this approach to difference. As a concrete result of these movements and broader postmodern discourses of difference, colleges, universities, businesses, government offices, and public spaces are more representatively differentiated than ever.

This said, the persistence of the modern legacy of subordinating difference to equality, along with mounting market imperatives toward individualized decision-making and the identification of the optimal with the optional, have not proven conducive to significantly alleviating (much less eliminating) social, economic, political, cultural, and technological inequities, but rather to displacing them in ways that constrain global common cause instead of coordinating it. The contemporary discourse of equity as equality of opportunity is perhaps useful in drawing attention to the aporia of difference, but not to breaking through it. For that, we need to delink equity and equality, and to conceive equity as a function of activating differences as the basis for sustained and fair mutual contribution. ${ }^{6}$

With this in mind, let me make use of zoos and ecosystems as metaphors for two distinct expressions of difference-that is, as significantly contrasting orientations and outcomes of differentiation processes. While a lavishly funded and ideally stocked zoo might contain all of the plants and animals that make up a particular ecosystem, their segregation in separate exhibits effectively

\footnotetext{
5 The literature of contemporary political engagements with issues of difference is vast, but a few key points of access are: Gutman and Thompson (1996); Taylor (1994); Honneth (1995); Thompson (2006); Young (1990); and Kymlicka (1995).

${ }_{6}$ This should not be construed as a justification, for example, of currently widening income, wealth and opportunity gaps within and among societies. Most certainly it is not intended to warrant the conservation of differences in relational advantages associated with such gaps. Rather, the point is to discern opportunities for using the existence of such differences to complement efforts to realize effective, equality-idealizing human rights regimes with efforts to enhance equity-realizing redresses of often deeply historical human wrongs. As should become evident, such redress cannot be either initiated or sustained on the basis of ignoring real differences—of economic status and class, or of culture and cognitive approaches-but only taking such differences into increasingly comprehensive and caring account.
} 
prohibits the realization of the relational dynamics that are constitutive of an ecosystem. Although the individual members of the species represented in a zoo are themselves complex organisms, they are not free to engage in complex interaction with one another. In short, they cannot interact in the ways that would bring about a self-organizing and novelty-generating complex system. Indeed, precisely because they are not linked with one another or their environments in substantially adaptive relations, their very survival in the zoo is dependent on the presence of such external environmental inputs as sunlight, food, water, electricity, medicines, and (especially) funding.

In sharp contrast, naturally occurring ecosystems are functionally open, self-organizing and selfsustaining systems in which individual species emerge and abide in unrestricted, complex interdependence. While the causalities operating in a zoo are largely linear, those in an ecosystem are nonlinear and decentralized, with influences and innovations propagating both upward and downward among nested systems and subsystems. Although species in an ecosystem can be seen as competing for scarce environmental resources, more accurately understood, each represents a distinctive approach to freeing up environmental resources and placing them into effective circulation. Evolutionary niches are not constrained spaces in which species take refuge. They are situationally specific resource frontiers opened through creatively expanded patterns of relational coordination. ${ }^{7}$

Although they might ideally contain the same number of different species, zoos are high in variety; ecosystems are high in diversity. Variety is a quantitative index of simple multiplicity that connotes things simply being-different. A function of either simple or complicated co-existence, variety is readily seen at a glance. Diversity is a qualitative index of self-sustaining and difference-enriching patterns of mutual contribution to shared welfare. A function of complex, coordination-enriching interdependence, diversification entails opening new modalities of interaction. As such, diversity is a relational achievement that emerges and becomes evident, if at all, only over time. Variety can be externally imposed; diversity cannot.

Thus, although it is possible to insure that a university seminar will contain students from a dozen countries, representing at least an equal number of cultural traditions, it is not possible to insure that this will result in anything other than a variety of cultural and national identities. Whereas cultural variety implies nothing more than factual co-existence, the realization of cultural diversity-whether in the classroom or the community-signals the emergence of a self-sustaining relational dynamic wherein cultural differences make meaningful differences in the overall creativity and adaptability of the class or community as a whole. Cultural diversity is, then, both the means-to and the meaning-of at once valuing and adding value to a shared situation through enhancing the significance of cultural difference.

To connect the variety-diversity distinction to the contemporary aporia of difference and the predicament laden nature of globalization dynamics, it is useful to note that the greatest ecological diversity does not occur - as might be expected - in the central core of a given ecosystem, but rather in the ecotone or zone of interaction among ecosystems. That is, ecological diversity is highest in regions of interdependence and interpenetration among individual ecosystems, where distinctively differing kinds of value can be drawn from environmental resources, sustaining distinctly different patterns of species well-being. More generally stated, diversity is greatest in zones of (value) system confluence and hence in circumstances particularly conducive to the occurrence of predicaments. This has the somewhat surprising implication that-in spite of the clear threats posed to ecological diversity by industrial modernization and its contemporary, reflexive manifestation-our highly predicament- and risk-laden world affords historically unparalleled potential for especially social, economic, political, cultural, and technological diversification. This potential might not be realized, of course, but it is crucial to our aim of more equitably orienting the dynamics of globalization to recognize the transformative possibilities

\footnotetext{
${ }^{7}$ Here it perhaps bears mentioning that one of the unfortunate legacies of the modern/market valorization of individuality and competition is an interpretation of nature as "red in tooth and claw" and of natural selection as a winner takes all race toward
} 
afforded by the often quite turbulent confluences of values and practices these dynamics make manifest.

\section{Education and Difference in a Complex, Predicament-Rich World}

How might the variety-diversity distinction help us re-envision education and to insure that education is not just passively compatible with, but rather actively conducive to greater equity both within and among societies, and across scales from the local to the global? Granted that diversity is, indeed, a relational achievement, the best answers to this question can be expected to emerge as different voices and perspectives find a common rhythm and sense of direction. With this in mind, let me nevertheless offer four cardinal points within which to frame this conversation.

First, today's educational crises are not problems; they are predicaments. Higher education is particularly sensitive to the dynamics within and among shifting arrays of often quite substantially conflicting public, private, social, economic, political, cultural and technological forces and interests. Indeed, it could be said with considerable justification that the primary drivers of educational shortfalls lie outside of the educational sector. That is, the key factors animating global consensus on the failures of higher education can be traced to conflicts within and among social, economic, political, cultural, and technological arcs of change, and the value complexes informing and orienting them. Addressing the crises of $21^{\text {st }}$-century higher education is not separable from addressing the wider crises associated with contemporary globalization processes and the aporia of difference with which they compel confrontation.

On the positive side, it must be noted that in a world of deep and complex interdependence and interpenetration, education is positioned not only to be affected by, but also to affect local, national, regional and global social, economic, political, cultural and technological dynamics. That is, precisely because higher education occurs at a uniquely intense and sensitive nexus of global dynamics, it is positioned to critically assess and help reorient the complex patterns of interdependence and interpenetration generated and sustained through them. Higher education systems-precisely because of their increasingly internationalized student bodies, curricular offerings, faculties, and organizational structures-provide high resolution insight into the dynamics of globally complex change, reflecting these dynamics at a usefully engaged scale. At the same time, they provide uniquely concentrated opportunities for generating diversity-enriching patterns of resolve, serving as nexuses for valuecoordination within and across both sectors and societies.

A second cardinal point is that this favorable positioning of higher education with respect to global dynamics should not be viewed over-optimistically. The "difference engines" of globalization and marketization have proven to be remarkably effective in forcing recognition that education in general and higher education more particularly are increasingly "out of step" with local, national, regional, and global realities. As we have already noted, this has led to mounting recognition that what we need are not incremental reforms, but rather paradigmatic revisions of the purposes and provision of education. Thus far, continued allegiance to modern commitments regarding the alignment of educational outputs with current market needs or inputs has led to attention being most powerfully focused on: questioning whether mass education is best provided as a public good or a market deliverable; shifting in the directing of student-centered and on-demand modes of instruction; exploring the efficiencies and effectiveness of various kinds of electronically mediated teaching and learning; responding to changing demographics and labor market fluctuations; and internationalizing campuses and curricula. In short, attention has been directed-quite rightly-to recognizing and responding to the fact that the ideal of a "one size fits all" approach to education is now thankfully defunct.

Yet there is considerable evidence that better aligning higher education with market dynamics and the simultaneously integrating and fragmenting dynamics of globalization, as they are now oriented, 
will lead to deepening education inequity —an increasing stratification of education quality, opportunity and outcomes (Rizvi, 2006). Critical attention must be directed to the likelihood that market-achieved "education for all" will almost surely not lead to "educational quality for all." To extrapolate from Ivan Illich's insight that the commodification of a subsistence need invariably leads to the institutionalization of a new class of the poor, the current "marketing" of lifelong learning may well be code for institutionalizing a global regime of compulsive, lifelong consumption of educational commodities. Higher education should not capitulate uncritically to neoliberal and market-fundamentalist justifications of inequality if the means-to and meaning-of higher education are to be aligned with enhancing both equity and diversity.

Third, this suggests that in considering the direction of higher education paradigm change, attention should be given to how to break through the aporia of difference posed by contemporary globalization processes in ways conducive to both expanding the reach and depth of social justice. Over the past half century, and with increasingly great traction at every scale from the local to the global, issues of difference have moved from the periphery to the center. Not only have such terms as "multiculturalism," "post-colonialism," and "gender" been added ineradicably to the lexicon of higher education, the very discourse and grammar of higher education is now inextricably tied to matters of difference and to concerns for justice and equity. As some proponents of multiculturalism have insisted, it is now increasingly clear that social justice and equity should not be seen as side-effects of education, but rather as values that can be effectively promoted only when infused into the full spectrum of educational activity "from the classroom to the boardroom," affecting training, practice, administration and institutional infrastructure, in full socioeconomic, political, technological, and cultural context.

Here, however, it is important to question whether the best means-to equitably addressing issues of difference are likely to emerge in the context of commitments to fusing the meaning-of equity to equality. One of the legacies of modernity generally and of liberalism more particularly is that all human beings should be granted equal respect and accorded equal rights to realizing their individual aims and interests. In keeping with this ideal, the prevailing conception of equity-prominently appealed to by intergovernmental organizations like the $\mathrm{UN}$-is that equity consists of realizing equality of opportunity (and perhaps in some degree, of outcomes). This has been a powerful conception, in both its more formal and substantive readings. And as it has been operationalized in higher education, it has played a crucial role in alleviating once stark disparities in educational access for men and women, for those with special physical needs, and for ethnic minorities. But there is no ultimate circumvention of the fact that equality is an essentially abstract function of sameness in relevant respects. Two people can be said to be the same only in some relevant respect, but not in their entirety as relationally constituted persons-in-community. Our universal equality is a fiction.

Now, to be sure, fictions can be very powerful. The transformative force of literature is testament enough to secure the effectiveness of fiction. And in the public sphere, there is no denying that the valorization of equality has played a crucial role, for example, in framing and establishing human rights regimes that at the very least evince the need to admit the existence of thresholds of indignity and to warrant the enjoyment of similar freedoms-of-choice by all in the pursuit of their own self-interest. Yet, institutional guarantees of equality can work against the emergence of diversity by overwriting our real and deep differences and translating associated potentials for mutual contribution into mere variety. If valorizing equity is to be a crucial means to breaking through the aporia of difference, it cannot be solely pegged to asserting fictions of sameness. For this, equity must be conceived as a qualitative transformation-not elimination —of difference.

One way of glossing such a relational conception is to see equity as a function of differences being brought into fair and apt coordination through the realization of shared clarity-about and commitments-to shared flourishing. In this sense, equity does not index achieved equality, but rather relationally manifest strengths for acting in our own self-interest, in ways deemed valuable by others. Equity and social justice are in this sense not promoted primarily by redistributions of power, where power is understood as the ability 
to exert control over or determine situational outcomes, but rather by enhancing strength, where strength connotes capacities for relating freely, contributing to situational dynamics in ways that appreciate or add value to interest-enhancing coordination.

This suggests, fourthly, that there ultimately can be no lasting equity without diversity. If education is going to enhance equity it must open spaces for the emergence of diversity. At present, much attention is given to promoting awareness about and celebrating "diversity" through, for example, cultural performances, international fairs, and more inclusive curricula. But while such efforts can insure more varied educational environments and practices, they cannot insure the emergence of diversity-enriching education in the strong sense of the term enjoined here. At the very least, opening spaces for diversity means conserving and appreciating - that is, valuing and adding-value-todifferences as the basis for mutual contribution. In keeping with the insight that diversity emerges most readily in predicament-rich zones of interaction among complex relational ecologies, this is not likely to be a conflict- or tension-free endeavor. Indeed, opening spaces for diversity would seem to entail a readiness to go beyond both the passive comforts of tolerance and the discomforts inflicted by intolerance.

One framework for envisioning the meaning of critically eschewing both tolerance and intolerance as stances toward difference is to see higher education engagements with difference as arrayed along a spectrum of positions between modern universalism and postmodern relativism. According to the former, everyone is fundamentally the same, and differences are best engaged as ultimately contingent facts. A position typically taken by institutionally recognized and empowered majorities, the universalist approach to difference is essentially one of assimilation. According to the latter, everyone is fundamentally unique, and differences must be engaged as unavoidable and irreducible facts. The relativist insists on the distinctive and ultimately incommensurable nature of presently disempowered minority perspectives, and typically resorts to a strategic focus on tolerating differences as an ineradicable feature of the human experience. Importantly, both universalist and relativist perspectives are in substantial agreement on the merits (and perhaps 'necessity') of effectively disarming difference. They are thus substantially at odds with enabling differences to truly make a difference in the way needed to realize, sustain and enhance diversity.

Educating for diversity concretely means shifting the locus of concern from how much we differfrom each other to how we might best differ-for one another. On one level, this means a programmatic shift from learning-about others to learning-from and learning-with one another, explicitly framing cultural encounters as opportunities for mutual contribution, especially in the context of developing resources for complex predicament resolution. A substantial body of work now makes evident that the task of innovatively addressing complex issues is best undertaken, not by individuals or groups of relevant experts, but rather by cognitively diverse groups (Page, 2007). At the very least, such work warrants efforts to promote more vigorously multidisciplinary and interdisciplinary approaches to education - a shift from higher education organized around disciplinary silos and independent "bodies of knowledge" to organizational dynamics that support the emergence of "ecologies of knowledge" and hence from satisfaction with epistemic variety to the pursuit of epistemic diversity.

At another level, however, while the problem-to-predicament transition makes concrete the need to question the continued dominance of the modern curricular paradigm that identifies education with the methodized delivery of standard, discipline-specific instructional content and skills building, the global nature of the predicaments we face suggest the need to move beyond a concern for epistemic or cognitive diversity toward a broader ethos of activating cultural differences as the basis for mutually sustained contribution to joint predicament-resolution and truly shared flourishing.

For some, of course, stressing cognitive and cultural plurality invites worries about social and political divisiveness, and focusing on our differences seems counterintuitive if our ultimate aim is to realize consensus on what might be called our "common good." And while I would hope that the conceptual distinction between cognitive and cultural variety and diversity would allay such worries by forcing recognition of the differentiated nature of difference itself, it still might be objected that it must 
nevertheless be the case that the working together requires a common ground: an internally coherent set of values and norms held in common. In some degree, this is undeniable. In the concrete context of higher education reform, for example, the need for common standards is a presumption of the socalled "articulation" efforts aimed at allowing credit transfers across institutional and national boundaries.

Yet, as Jean-Luc Nancy (1991) has pointedly argued, there are also reasons to question the proper scope of assuming the necessity of appeals to a "common nature," a "common heritage," and "common values." After all, such appeals to a common culture undergirded the predatory stance of Nazi fascism regarding issues of difference, and assumptions about the existence of a universal human nature and of the universality of modern values warranted much of the plowing under of cultural differences pursued for the "common good" by various modern imperialisms. Alert to the dangers of appealing to transcendent forms of unity or sameness, Nancy insightfully stresses as an alternative the productive nature of difference that is encapsulated in the notion of sharing (partage) —a term that connotes partaking jointly in something (hospitably) divided, but also and more importantly, bringing something distinctive to a joint endeavor, as in sharing a meal or a dance. Sharing in this sense is a relational modality wherein those brought together contribute to realizing something that qualitatively exceeds whatever any of them individually might have realized.

Stressing the activation of differences as opportunities for mutual contribution oriented toward shared flourishing rather than a common good offers insurance, first, against the kind of transcendentreductionism that, for example, would transmute the play of cultural differences into a norm of cosmopolitanism; and, secondly, against the kind of immanent-reductionism that, for example, would translate all cognitive differences into varying (and perhaps hierarchically arrayed) expressions of a particular science (e.g., physics or neurochemistry) or the rationality-defining equivalent of a Kantian categorical substrate. In Nancy's terms, refraining from marshalling different epistemic and cultural perspectives to pursue a common good is crucial to insuring that orienting higher education in such a way as to support and sustain shared and diversity enriching predicament-resolution does not result ironically in the modern default of collapsing variety into unity.

This shift of emphasis from the common to the shared suggests further that while educating for equity cannot be entirely divorced from efforts to realize equality of access or from quantitative concerns about who is included and who remains excluded from higher education, it is more properly focused on discerning how most effectively and sustainably to enable the differences of each to make a significant difference for all. This implies a shift away from an exclusive focus on the epistemic modalities of knowing-that and knowing-how that are best suited to the needs of problem-solution, to a resolutely inclusive approach that warrants the critical significance of knowing-to as an epistemic modality crucial both in responding to risk and in predicament-resolution. In short, equity-enhancing higher education involves undoing the divorce of the technical and the ethical—a healing of the modern schism of knowledge and wisdom.

Undertaken in pursuit of the diversification of higher education, such a healing trajectory should not be seen as implying a convergence on either a particular morality (the way "we" do things) or a particular ethics (the way "everyone" should do things), but rather as one of ramification or radiance. Concretely, this healing of the schism between knowledge and wisdom accords well with efforts to consolidate curricular and extra-curricular commitments to educating "whole persons" and to expanding concerns for market-alignment to include concerns for social and cultural fit. It also points toward expanding medical and media ethics programs, for example, beyond their existing focus on identifying and enforcing professional standards to take explicitly into account how best to engage questions about the purposes of medicine and media to foster the emergence of diversity- and equityenhancing medical and media activities. 


\section{Concluding Remarks}

If already ongoing changes in higher education are seen as accurately reflecting and addressing dominant patterns in the social, economic, political, technological, and cultural dynamics of globalization, the overwhelming evidence is that the general thrust of these imperatives is directed toward increasing differentiation. Recognizing this, however, especially in the context of manifestly deepening inequalities both within and among societies, is to recognize the need to question whether the arcs of change in higher education should remain passively entrained with the magnifications and multiplications of difference taking place as a function of globalization processes, as currently oriented.

My own conviction is that higher education can and should play a unique and critical role in reorienting the dynamics of global interdependence. To date, higher education has been primarily aligned with meeting market needs and shoring up local and national political platforms, servicing the "engines of inequity" powering contemporary globalization processes. The conceptual lenses offered above open prospects on reframing higher education as an ethically charged nexus of human and epistemic resources suited to realizing and strengthening the kinds and qualities of relational networks needed to resolve the widening and deepening arrays of predicaments with which we are being confronted locally, nationally, regionally and globally. Key to this will be struggling with how most effectively to inflect the differentiation processes already ongoing in higher education away from continued variation toward deepening diversification. If current trends toward interdisciplinary studies, flexible specialization, internationalization, and cross-border education can be turned to producing conditions for the emergence of diversity, higher education may yet come to serve as a truly global relational commons through which our differences are activated in service of shared and ever more equitably realized expressions of global public good.

\section{References}

Appadurai, Arjun (1996). Modernity at large: Cultural dimensions of globalization. Minneapolis: Minnesota University Press.

Beck, Ulrich (with A. Giddens and S. Lash) (1994). Reflexive modernization: Politics, tradition and aesthetics in the modern social order. Stanford CA: Stanford University Press.

Beck, Ulrich (1999). World risk society. London: Polity Press.

Castells, Manuel (1996). The rise of the network society. The information age: Economy, society and culture, Vol. I. Cambridge, MA: Blackwell.

Castells, Manuel (1997). The power of identity. The information age: Economy, society and culture, Vol. II. Cambridge, MA: Blackwell.

Castells, Manuel (1998). End of millennium. The information age: Economy, society and culture, Vol. III. Cambridge, MA: Blackwell.

De Zengotita, Thomas (2005). Mediated: How the media shapes the world and the way you live in it. New York: Bloomsbury Press.

Doll, William E. Jr. (1993). A postmodern perspective on curriculum. New York: Teachers College Press.

Doll, William E. Jr., \& Gough, N. (2002). Curriculum visions. New York: Peter Lang.

Franck, Georg (1998). Ökonomie der Aufmerksamkeit [Economy of attention]. Munich: Carl Hanser Verlag.

Guttman, Amy, \& Thompson, D. (1996). Democracy and disagreement. Cambridge, MA: Belnap Press of Harvard University Press.

Harvey, David (1996). Justice, nature and the geography of difference. London: Blackwell.

Harvey, David (2006). Spaces of global capitalism: Towards a theory of uneven geographical development. London: Verso. 
Hawkins, John N. (2007). The intractable dominant educational paradigm. In Peter D. Hershock, M. Mason \& J. N. Hawkins (Eds.), Changing education: Leadership, innovation and development in a globalizing Asia Pacific. Hong Kong: Springer/CERC.

Hershock, Peter D. (1999). Reinventing the wheel: A Buddhist response to the information age. Albany, NY: State University of New York Press.

Hershock, Peter D. (2007a). Education and alleviating poverty: Educating for equity and diversity. In Peter D. Hershock, M. Mason \& J. N. Hawkins (Eds.), Changing education: Leadership, innovation and development in a globalizing Asia Pacific. Hong Kong: Springer/CERC.

Hershock, Peter D. (2007b). Leadership in the context of complex global interdependence: Emerging realities for educational innovation. In Peter D. Hershock, M. Mason \& J. N. Hawkins (Eds.), Changing education: Leadership, innovation and development in a globalizing Asia Pacific. Hong Kong: Springer/CERC.

Hershock, Peter D. (2006). Buddhism in the public sphere: Reorienting global interdependence. London: Routledge.

Honneth, Axel. (1995). The struggle for recognition: The moral grammar of social conflicts. Cambridge: Polity Press.

Kymlicka, Will (1995). Multicultural citizenship. Oxford: Oxford University Press.

Kuhn, Thomas S. (1996). The structure of scientific revolutions. Chicago: University of Chicago Press.

Lanham, Richard A. (2006). The economics of attention: Style and substance in the age of information. Chicago: University of Chicago Press.

Lash, Scott (2002). Critique of information. London: Sage Publications.

Luhmann, Nicholas (2000). The reality of the mass media (K. Cross, Trans.). Stanford, CA: Stanford University Press.

Nancy, Jean-Luc (1991). The inoperative community (P. Connor, Ed.; P. Connor, L. Garbus, M. Holland, and S. Sawhney, Trans.). Minneapolis: University of Minnesota Press.

Page, Scott (2007). The difference: How the power of diversity creates better groups, firms, schools and societies. Princeton, NJ: Princeton University Press.

Rizvi, Fazal (2007). Rethinking educational aims in an era of globalization. In Peter D. Hershock, M. Mason \& J. N. Hawkins (Eds.), Changing education: Leadership, innovation and development in a globalizing Asia Pacific. Hong Kong: Springer/CERC.

Robinson, William I. (2004). A theory of global capitalism: Production, class, and state in a transnational world. Baltimore: Johns Hopkins University Press.

Rosenau, James N. (2003). Distant proximities: Dynamics beyond globalization. Princeton, N.J.: Princeton University Press.

Stiglitz, Joseph E. (2003). Globalization and its discontents. New York: Norton.

Taylor, Charles (1994). Multiculturalism: Examining the politics of recognition. Princeton: Princeton University Press.

Taylor, Mark C. (1987). Altarity. Chicago: University of Chicago Press.

Thompson, Simon (2006). The political theory of recognition: A critical introduction. Cambridge, UK: Polity Press.

Toulmin, Stephen (1990). Cosmopolis: The hidden agenda of modernity. Chicago: University of Chicago Press.

Tyack, David, \& Cuban, L. (1995). Tinkering toward utopia: A century of public school reform. Cambridge: Harvard University Press.

Young, Iris Marion (1990). Justice and the politics of difference. Princeton: Princeton University Press.

\section{About the Author}

Peter D. Hershock is Coordinator of the Asian Studies Development Program at the East-West Center in Honolulu, Hawai'i, and holds a doctorate in Asian and comparative philosophy. His research focuses 
on the relevance of Asian philosophical perspectives in addressing such contemporary issues as: technology and development, education, human rights, and the role of values in cultural and social change. hershocp@eastwestcenter.org 